\title{
Millimeter-Wave Photonic Components for Broadband Wireless Systems
}

\author{
(invited paper)
}

\begin{abstract}
Andreas Stöhr, Senior Member, IEEE, Paul Cannard, Benoît Charbonnier, Frédéric van Dijk, Sascha Fedderwitz, Dave Moodie, Leon Pavlovic, Lalitha Ponnampalam, Cyril C. Renaud, Member, IEEE, Dave Rogers, Vitaly Rymanov, Alwyn Seeds, Fellow, IEEE, Andreas Steffan, Andreas Umbach, and Mario Weiß
\end{abstract}

\begin{abstract}
We report on advanced millimeter-wave (mm-wave) photonic components for broadband wireless transmission.

We have developed self-pulsating $60 \mathrm{GHz}$ range quantumdash Fabry-Perot mode-locked laser diodes (MLLD) for passive, i.e. unlocked, photonic mm-wave generation with comparably low phase noise level of $-76 \mathrm{dBc} / \mathrm{Hz} @ 100 \mathrm{kHz}$ offset from $58.8 \mathrm{GHz}$ carrier. We further report on high-frequency $1.55 \mu \mathrm{m}$ waveguide photodiodes (PD) with partially p-doped absorber for broadband operation ( $\left.f_{3 \mathrm{~dB}} \sim 70-110 \mathrm{GHz}\right)$ and peak output power levels up to $+4.5 \mathrm{dBm} @ 110 \mathrm{GHz}$ as well as wideband antenna integrated photomixers for operation within $30-300 \mathrm{GHz}$ and peak output power levels of $-11 \mathrm{dBm} @ 100 \mathrm{GHz}$ and $6 \mathrm{~mA}$ photocurrent.

We further present compact $60 \mathrm{GHz}$ wireless transmitter and receiver modules for wireless transmission of uncompressed 1080p (2.97 Gb/s) HDTV signals utilizing the developed MLLD and mm-wave PD. Error-free (BER $=10^{-9}, 2^{31}-1$ PRBS, NRZ) outdoor transmission of $3 \mathrm{~Gb} / \mathrm{s}$ over $25 \mathrm{~m}$ is demonstrated as well as wireless transmission of uncompressed HDTV signals in the $60 \mathrm{GHz}$ band. Finally, an advanced $60 \mathrm{GHz}$ photonic wireless system offering record data throughputs and spectral efficiencies is presented. For the first time, we demonstrate photonic wireless transmission of data throughputs up to $27.04 \mathrm{Gbit} / \mathrm{s}$ (EVM $17.6 \%$ ) using a 16-QAM OFDM modulation format resulting in a spectral efficiency as high as $3.86 \mathrm{bit} / \mathrm{s} / \mathrm{Hz}$. Wireless experiments were carried out within the regulated $57-64 \mathbf{G H z}$ band in a lab environment with a maximum transmit power of $-1 \mathrm{dBm}$ and $23 \mathrm{dBi}$ gain antennas for a wireless span of $2.5 \mathrm{~m}$. This span can be extended to some $100 \mathrm{~m}$ span when using highgain antennas and higher transmit power levels.
\end{abstract}

Manuscript received XXXX, 2010.

A. Stöhr, S. Fedderwitz, V. Rymanov and M. Weiß are with Universität Duisburg-Essen, Duisburg, Germany (e-mail: andreas.stoehr@uni-due.de).

B. Charbonnier is with France Télécom Research and Development, $2 \mathrm{Av}$. Pierre Marzin, 22300 Lannion, France.

F. van Dijk is with Alcatel-Thalès III-V Lab, 1 avenue A. Fresnel 91767 Palaiseau cedex, France.

D. Moodie, D. Rogers, and P. Cannard are with CIP Technologies Ltd., Ipswich, United Kingdom.

L. Ponnampalam, C. C. Renaud, and A. Seeds are with University College London, Department of Electronic and Electrical Engineering, Torrington Place, London WC1E 7JE, United Kingdom.

L. Pavlovic is with University of Ljubljana, Faculty of Electrical Engineering, Trzaska 25, 1000 Ljubljana, Slovenia.

A. Steffan and A. Umbach are with $\mathrm{U}^{2} \mathrm{~T}$ Photonics AG, Berlin, Germany.
Index Terms-Radio-over-Fiber, Mode-Locked Laser, Millimeter-Wave Photodiodes, Wireless Communications

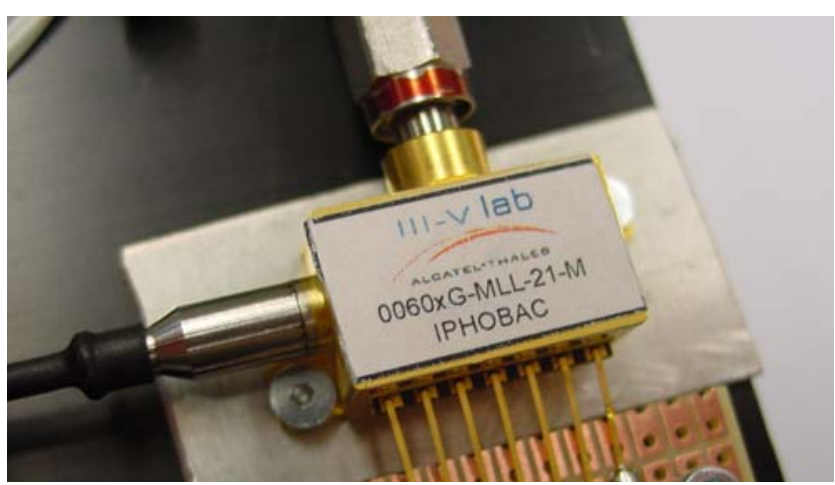

Fig. 1 Packaged $60 \mathrm{GHz}$ mode-locked laser diode.

\section{INTRODUCTION}

Since the early experiments in the late 1970s, the field of Microwave Photonics has expanded significantly. In recent times, the technology has matured as a disruptive alternative for several radio-frequency applications. This has been fueled on the one hand by increasing performances and reliability of photonic component technology and on the other hand by the ever increasing operating frequencies of many RF applications. Today, a considerable number of commercial applications are already being addressed by Microwave Photonics [1], some of these applications have yet already achieved a substantial annual sales market in the order of 100 $\mathrm{M} €$ [2], others are more in a proof-of-concept status [3]. According to a recent survey, the interest in Microwave Photonic technologies is especially strong in a growing number of applications utilizing the millimeter-wave frequency range (30-300 GHz) [4]. Therefore, the European Commission has supported advanced Microwave Photonic component and system technology developments within the IPHOBAC (Integrated Photonic mm-Wave Functions for Broadband Connectivity) project for addressing future applications in communications, radar/sensing and instrumentation [5].

It is the objective of this article to report on some of the recent component developments achieved within IPHOBAC as well as on their utilization in broadband wireless systems. 
With respect to component developments, the focus will be on mode-locked $60 \mathrm{GHz}$ Fabry-Perot (FP) laserdiodes for lowphase noise millimeter-wave generation as well as upon highoutput power broadband (DC-110 GHz) photodiodes and wideband (30-300 $\mathrm{GHz})$ antenna integrated photomixers. Hereafter, compact wireless transmitter and receiver modules for wireless transmission of uncompressed HDTV signals in the $60 \mathrm{GHz}$ band will be reported as well as advanced $60 \mathrm{GHz}$ radio-over-fiber systems utilizing spectrally efficient modulation formats. Finally, ultra-broadband wireless transmission with record data rates and spectral efficiencies within the regulated 57-64 GHz band will be demonstrated.

\section{II. $60 \mathrm{GHz}$ Mode-Locked LASER Diode}

For generating mm-wave signals with comparably lowphase noise levels and without the need of any locking scheme, we have developed self-pulsating MLLDs for $60 \mathrm{GHz}$ band operation (see Fig. 1 for packaged MLLD component). The semiconductor laser chip that was used for our experiment is made of a buried ridge structure, and contains an active layer based on quantum dots (QD) on InP substrate. The vertical structure was described in a previously published work [6]. Both facets are cleaved, forming a $710 \mu \mathrm{m}$ long FP cavity. The QD-FP laser was packaged in a module. This laser exhibits a very wide optical spectrum with a $-3 \mathrm{~dB}$ bandwidth of more than $10 \mathrm{~nm}$, as can be seen in Fig. 2.

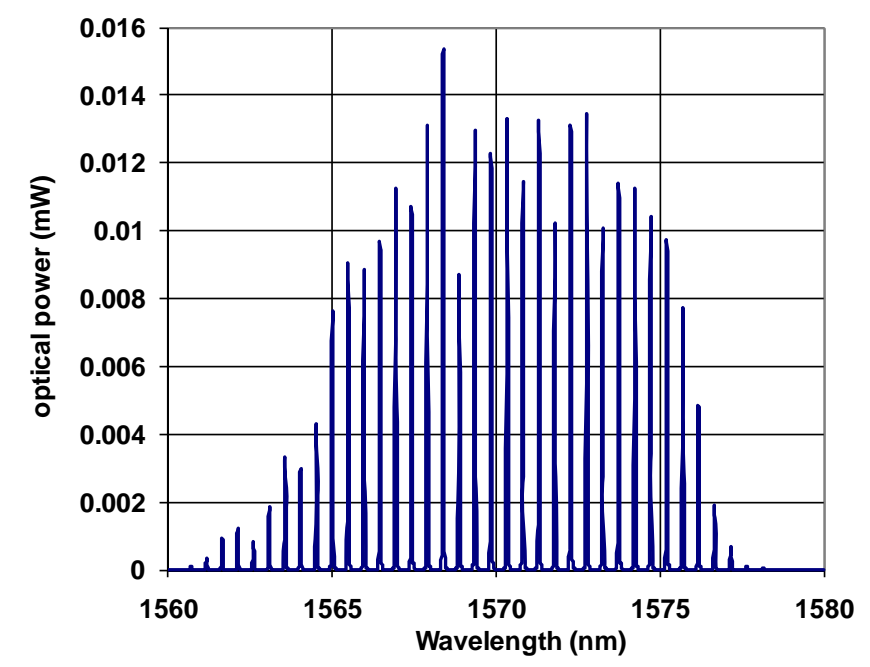

Fig. 2 Optical spectrum at a bias current of $211 \mathrm{~mA}$.

Passive mode-locking at a mode-locking frequency $\left(\mathrm{f}_{\mathrm{ML}}\right)$ of $58.8 \mathrm{GHz}$ has been obtained with these devices without the use of any specific saturable absorber. The $-3 \mathrm{~dB}$ linewidth of the beat note generated after photodetection was below $20 \mathrm{kHz}$. The phase noise obtained from this signal was downconverted to $320 \mathrm{MHz}$ using an Agilent $11970 \mathrm{U}$ harmonic mixer associated to a reference source and measured using the phase noise function of a Rohde\&Schwarz FSEK30 electrical spectrum analyzer (ESA). The single side band (SSB) phase noise measurement result is presented in Fig. 3. At an offset frequency of $10 \mathrm{kHz}$, the phase noise exhibits a value of $-54.4 \mathrm{dBc} / \mathrm{Hz}$. The extremely narrow linewidth for QD lasers is believed to be a consequence of reduced spontaneous emission rate coupled to the lasing mode, and sufficient four wave mixing in these QD structures [7].

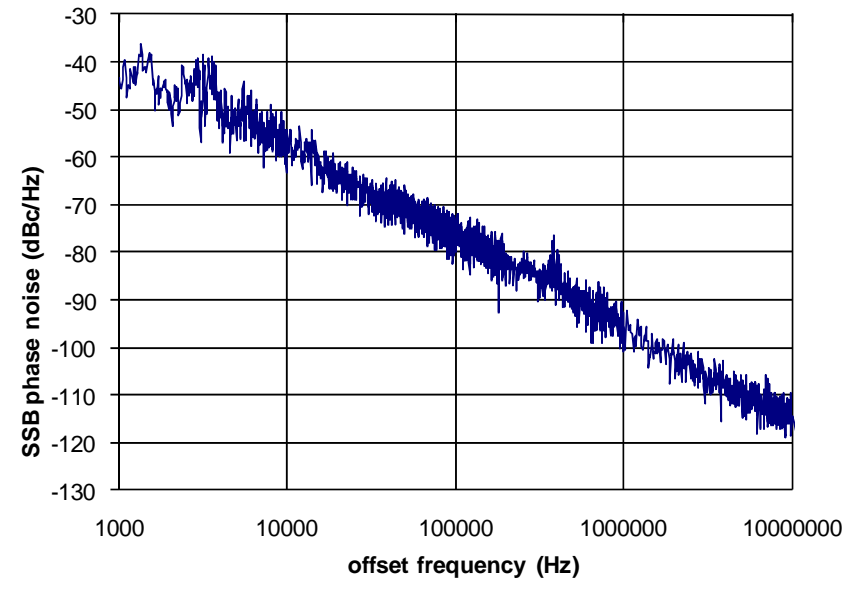

Fig. 3 Single side band phase noise of the $58.8 \mathrm{GHz}$ tone generated by the laser at a bias current of $211 \mathrm{~mA}$.

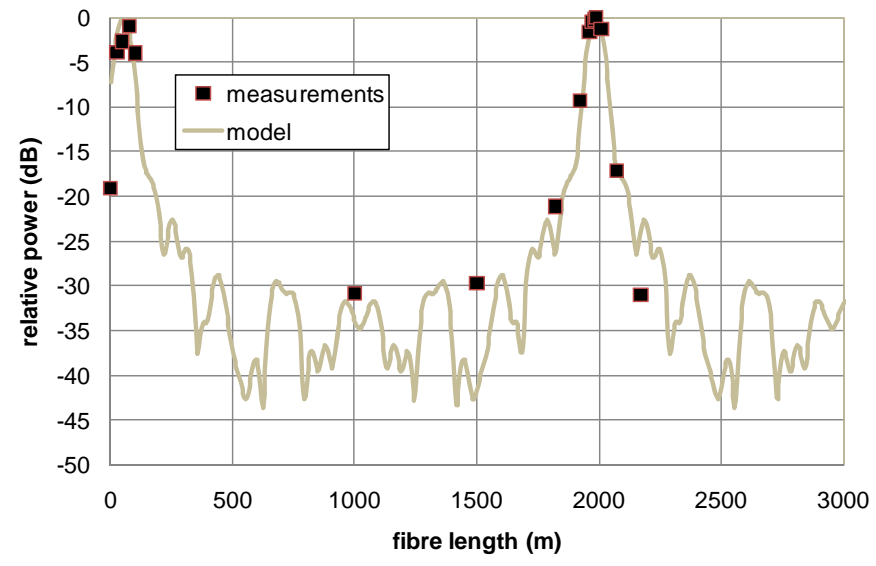

Fig. 4 Corrected photodetected electrical power as a function of fiber length.

The o/e-converted power from a mode-locked laser source is obtained thanks to the beating of the couples of optical modes during the photodetection process. If there is a phase difference between the optical modes it will also affect the electrical beat notes and thus the power of the sum of all the beat notes at $\mathrm{f}_{\mathrm{ML}}$ as explained in [8]. If the phase dispersion in the optical spectrum is compensated using the group index dispersion of an optical fiber, it is possible to minimize the phase dispersion between all the electrical beat notes and hence to maximize the generated power at $f_{\mathrm{ML}}$. We have measured the electrical power after photodetection from the mode-locked laser. Detection was made using a $70 \mathrm{GHz}$ photodiode from $\mathrm{U}^{2} \mathrm{~T}$. The electrical power at $f_{\mathrm{ML}}$ was measured using an Agilent E4448A ESA coupled to a V-band (50-75 GHz) HP $11974 \mathrm{~V}$ preselected harmonic mixer. The measurements were performed after propagation through different lengths of standard single mode fiber. Fig. 4 presents the results of these measurements (squares) with a correction used to remove the contribution of the coupling losses 
associated to the numerous sections that had to be used and normalized to $0 \mathrm{~dB}$. It can be seen that it is possible to increase the generated electrical power by about $20 \mathrm{~dB}$ just by adding $78 \mathrm{~m}$ of standard single mode optical fiber thus compensating the phase difference between the modes.

\section{High-OUTPUT POWER DC-110 GHz PHOTODETECTORS}

Work on uni-travelling carrier (UTC) [9], [10] and partially depleted absorber waveguide photodetectors (PD) [11] was also developed to investigate the potential advantages of the faster carrier drift velocity in both devices. The first set of devices under study was a waveguide UTC PD, without any mode convertor to couple the optical input. These devices showed relatively high responsivity $(0.36 \mathrm{~A} / \mathrm{W})$ with a wide bandwith $(110 \mathrm{GHz})$ and high saturation $(36 \mathrm{~mA}$ photocurrent and $10 \mathrm{dBm}$ extracted power at $110 \mathrm{GHz}$ ) [12]. Following this work which had demonstrated the advantages of such fast photodetectors for photonic generation of high frequency signals (from $60 \mathrm{GHz}$ to $300 \mathrm{GHz}$ ) further work was done in developing a PD integrated with a mode converter, in order to try and improve the responsivity of the device and make them more suitable for packaging. This mode-expanded PD used a similar active design as the previously developed devices, although they were designed to have a partially p-doped absorber layer rather than an UTC structure. The modeexpanded photodiodes were fabricated to a multi-level ridge waveguide design, shown schematically in Fig. 5 . A $1 \mathrm{~mm}$ long double stage taper was employed. Its purpose was to match the mode at the facet to that of a cleaved fiber or that of a passive silica waveguides used on silicon motherboards for hybrid integrated devices as in [13], while delivering relatively tightly confined light into the active region to maximize the responsivity of a short low capacitance active region.

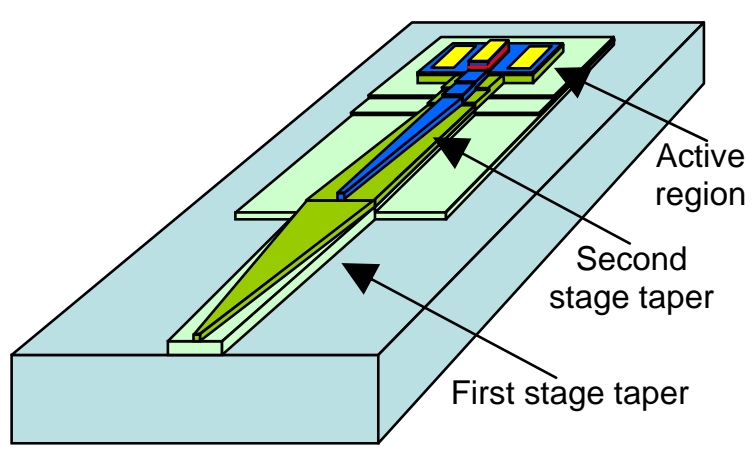

Fig. 5 Mode-expanded photodiode chip.

Fabricated chips also incorporate precision cleave and scribe features (Fig. 6). The design of the mode converter offered the further advantage of a polarization sensitivity typically as low as $0.5 \mathrm{~dB}$. Chip capacitances comprised the parasitic capacitance of the coplanar electrode structure $\sim 11 \mathrm{fF}$ and the active capacitance. Chips with intended active region dimensions of $20 \mu \mathrm{m} \times 2.8 \mu \mathrm{m}$ had an average active region capacitance measured at $1 \mathrm{MHz}$ and $-2 \mathrm{~V}$ bias of $33 \mathrm{fF}$.
This would give an idealized RC limited bandwidth of $\sim 96 \mathrm{GHz}$ with no matching circuit when $\mathrm{R}=50 \Omega$. The series resistance estimated from Smith chart traces was $\sim 19 \Omega$.

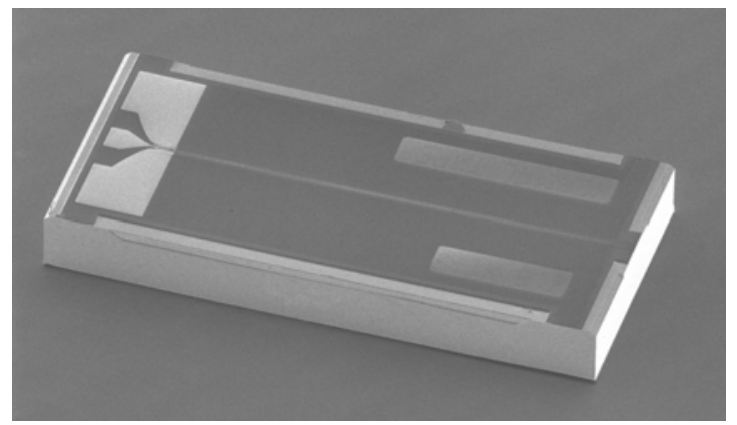

Fig. 6 SEM micrograph of photodiode with coplanar electrodes.

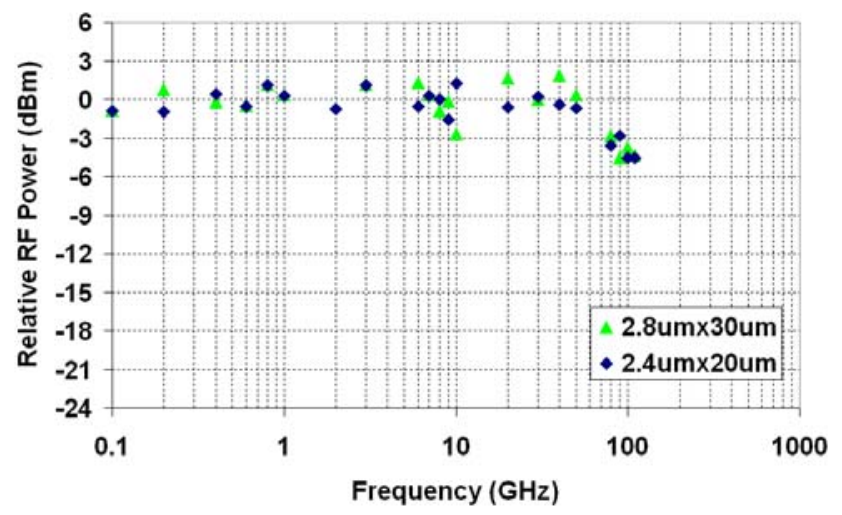

Fig. 7 Frequency response of photodiode chips measured using coplanar probes and an optical heterodyne system.

These devices were measured for frequency response up to $110 \mathrm{GHz}$. For these measurements a heterodyne generation system was used [14] that offers high frequency purity from $10 \mathrm{GHz}$ to $1.5 \mathrm{THz}$. Fig. 7 shows the frequency response for two different devices with different absorption lengths. These devices achieved up to $0.45 \mathrm{~A} / \mathrm{W}$ for $\mathrm{f}_{3 \mathrm{~dB}} \sim 100 \mathrm{GHz}$, while devices with longer and wider absorption length showed up to $0.6 \mathrm{~A} / \mathrm{W}$ responsivity for a 3dB-bandwidth of $\mathrm{f}_{3 \mathrm{~dB}} \sim 70 \mathrm{GHz}$. These results showed clearly that the double taper mode converter design was efficient as it could increase the responsivity of the devices with little impact on the frequency response. However, these devices showed saturation from $15 \mathrm{~mA}$ to $20 \mathrm{~mA}$ (longer devices) of photocurrent, while under temperature control, suggesting more of a space charge effect in the depletion region compared to the earlier devices. Under these conditions the devices still allowed for up to +4.5 $\mathrm{dBm}$ to be extracted at $110 \mathrm{GHz}$.

The mode-expanded photodiodes were also tested in an integrated frequency generation system that included a reference optical frequency comb generator (OFCG) based on the quantum dot MLLD descried above and a dual DBR integrated laser module. The OFCG offered a set of narrow linewidth optical frequency lines spaced by $24 \mathrm{GHz}$ over a span of $1.6 \mathrm{THz}$ [15]. The monolithically integrated dual DBR laser gave two outputs combined by an integrated MMI 
coupler which was further integrated onto an angle tapered semiconductor optical amplifier (SOA) to boost the output power with minimum facet reflections. The dual DBR was injection locked on two of the comb lines and could offer tuning for the heterodyne signal up to $1.8 \mathrm{THz}$ [15], this signal was then injected into the photodetector described previously without any external amplification offering a $2 \mathrm{~mA}$ photocurrent. While the frequency and emission power performances were similar to what was measured previously with the photodetectors, one could see in Fig. 8 that the resulting signal at $98 \mathrm{GHz}$ was retaining the frequency purity of the OFCG reference source, which had a phase noise level of $-70 \mathrm{dBc} / \mathrm{Hz}$ at $10 \mathrm{kHz}$ offset.

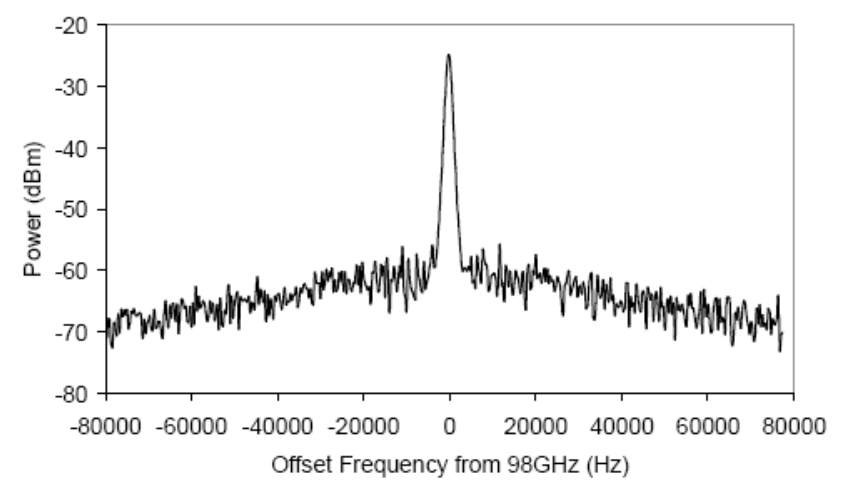

Fig. 8 Heterodyne generated signal at $98 \mathrm{GHz}$ from a fast photodetector using an integrated photonic system.

In our opinion, those results clearly demonstrate the potential for these fast photodetectors to be used within a photonic high frequency purity generator for frequencies above $60 \mathrm{GHz}$.

\section{High-OutPut POWER 30-300 GHz PHOTOMIXERS}

In this section, we report on a compact antenna-integrated photonic mm-wave transmitter employing a traveling-wave (TW) photomixer based upon an InP-based pin double waveguide structure.

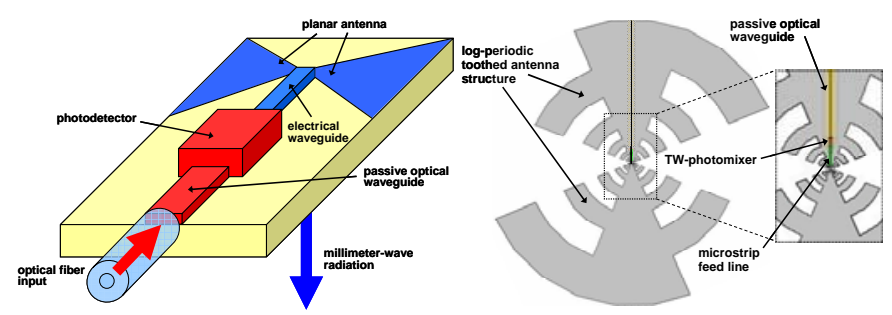

Fig. 9 Operation principle (left hand) and schematic structure of the developed component comprising passive optical waveguide, photomixer, low-loss antenna feed and a broadband LPTA-structure (right hand).

Fig. 9 shows a schematic of the antenna-integrated photomixer. An optical heterodyne signal is coupled via a single mode fiber (SMF) into a passive optical waveguide (POW) which further guides the optical signal to the antenna integrated photomixer operating within the whole mm-wave range (i.e. 30-300 GHz). After photomixing of the optical heterodyne signal, the converted electrical signal is coupled to an electrical microstrip waveguide connecting the photomixer to the feeding point of a planar antenna. Due to the large difference in the dielectric constant between air and semiconductor substrate, the generated mm-wave is mainly $(\sim 92 \%)$ radiated through the substrate. For efficient beamforming and coupling to free-space an additional hemispherical Silicon lens is used as reported in [16]. For achieving a wide frequency tuning range, the photomixer was integrated with a broadband planar log-periodic toothed antenna (LPTA) as can be seen in Fig. 9.

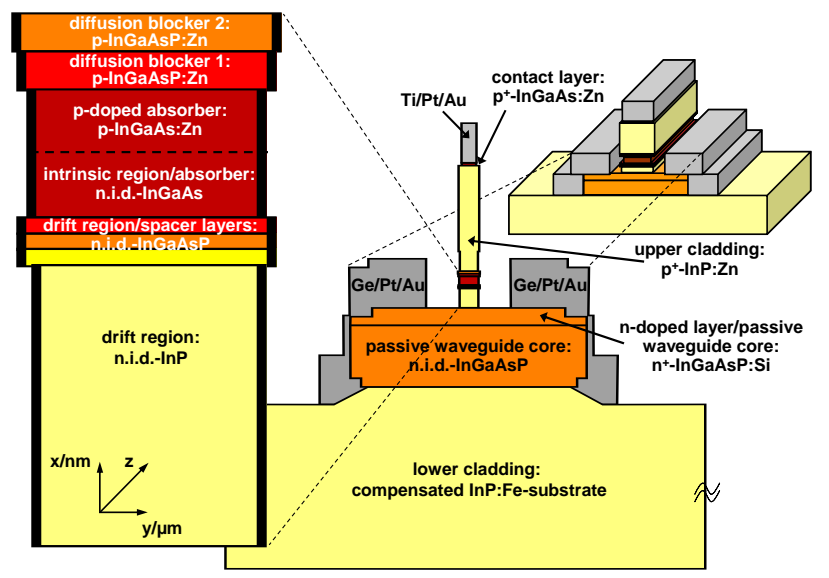

Fig. 10 Schematic cross section (middle) of the developed traveling-wave photomixer, enlarged active section (left hand) and 3-dimensional model (right hand).

The cross section of the InP layer structure used for the photomixer is schematically shown in Fig. 10. Our approach comprises a traveling-wave pin waveguide structure using a partially p-doped absorbing layer and a partially nonabsorbing intrinsic layer. This structure, in conjunction with a thin absorber in the drift region is expected to exhibit high photocurrent saturation without compromising the frequency response [17], [18] . Another key benefit is the applied traveling wave principle, which differs from a lumped element in a non-RC time limited response exhibiting superior highfrequency performances. This was already demonstrated e.g. in [19]-[21].

In detail, the active core consists of a partially p-doped absorbing InGaAs layer $(50 \mathrm{~nm})$ as well as a non-intentionally doped absorbing InGaAs layer $(50 \mathrm{~nm})$. The drift region featuring three InGaAsP spacer layers and the InP layer is located below the intrinsic absorber. The thickness of the nonabsorbing InP drift layer is $220 \mathrm{~nm}$.

This layer ensures that the applied field is dropped across the whole drift region. By varying the thickness of this layer, the overlap of the optical mode with the absorber can be adjusted. As a result, a lower overlap factor and thus a longer absorption profile and in turn a more uniform distribution of photo-generated carriers along the length of the active photomixer section is achieved. This reduces saturation effects at the front facet and enhances the overall photocurrent saturation of the photomixer [22]. For guiding the optical 
heterodyne signal from the SMF to the active section which is located at the feeding point of the antenna, an additional striploaded InGaAsP/InP POW consisting of two InGaAsP layers has been grown underneath the active waveguide which is shown in Fig. 9 and Fig. 10. BPM CAD simulations were carried out to calculate the overall optical coupling efficiency from a lensed SMF to the active photomixer. Here, it was found, that the maximum efficiency is as high as $73 \%$ provided a proper geometrical design is applied. Photoluminescence wavelength for the non-absorbent core was determined to be $1.21 \mu \mathrm{m}$ at room temperature which indicates that the photomixer can be operated not only at $1.55 \mu \mathrm{m}$ but also at $1.3 \mu \mathrm{m}$.

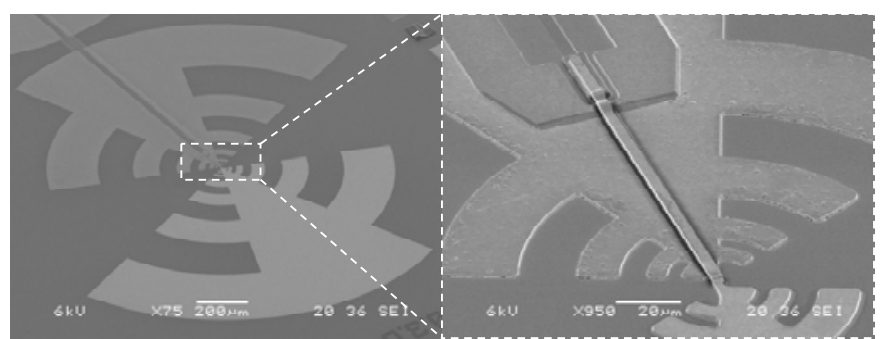

Fig. 11 SEM-photographs of the developed photonic transmitter chip. Top view of the fabricated antenna-integrated photomixer (left hand) and close-up view of the center of the LPTA structure with microstrip circuitry, active photomixer section and passive optical waveguide (right hand).

In Fig. 11, the realized antenna-integrated photomixer is illustrated, comprising of a $2 \times 2 \mathrm{~mm}^{2}$ log-periodic antenna and an approx. $1 \mathrm{~mm}$ long POW for optical feed, extending from the front surface to the active photomixer section. The photomixer, exhibiting a $100 \mu \mathrm{m}$ microstrip feed line between the active photomixer section and the antenna center, is positioned close to antenna center for low electrical losses between photomixer output and antenna feeding point. Calculated results show an input return loss around $-20 \mathrm{~dB}$ up to $300 \mathrm{GHz}$ for the integrated electrical waveguide circuitry.

The pattern and directivity of the integrated planar LPTAs were studied using FEM and FDTD. It was found, that the directivity increases from $8 \mathrm{dBi}$ at $30 \mathrm{GHz}$ up to $25 \mathrm{dBi}$ at $300 \mathrm{GHz}$ and that the input antenna impedance is in the order of $74 \Omega$ [16].

For measuring the power generated by the fabricated device from 30-300 GHz, a set of narrow-band waveguide-coupled Schottky diode power detectors (WR22, WR15, WR10, WR8, WR5, WR3) with attached horn antennas was used. The measured relative frequency response of the fabricated antenna integrated photomixer is shown in Fig. 12. As can be seen from that figure, the received power drops only by approximately $16 \mathrm{~dB}$ over the full frequency range of 30-300 $\mathrm{GHz}$ which is traced back to the traveling wave concept. Additionally, we investigate the polarization dependency between the receiving horn antennas and the transmitter modules. Experimentally, a maximum polarization dependent variation of the output power of 3-5 dB was found.

For comparison, all chips were measured at a photocurrent level of only $1 \mathrm{~mA}$. Here, the maximum power received in the
Schottky detectors was $-23.3 \mathrm{dBm}$ at $33 \mathrm{GHz},-26.6 \mathrm{dBm}$ at $100 \mathrm{GHz},-33.4 \mathrm{dBm}$ at $200 \mathrm{GHz}$ and $-38.3 \mathrm{dBm}$ at $300 \mathrm{GHz}$.

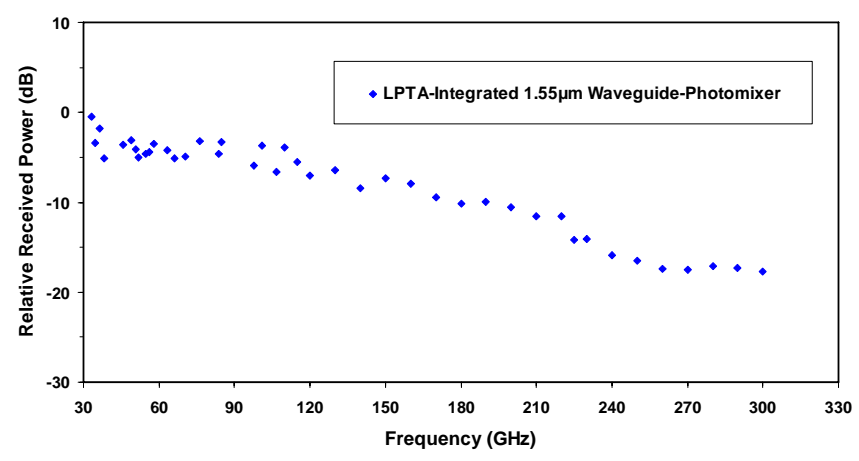

Fig. 12 30-300 GHz characterization of the developed photomixer using a set of narrow-band Schottky diode power detectors.

As can be extracted from Fig. 13, the received power increases linearly with the photocurrent up to $6 \mathrm{~mA}$. Thus, approx. 15.6 dB higher output power levels are achieved when operating at $6 \mathrm{~mA}$. Currently, the maximum photocurrent is limited to $6 \mathrm{~mA}$ due to the POW and a lack of a high-output power EDFA, for PDs without the POW photocurrent levels of $30 \mathrm{~mA}$ have been achieved.

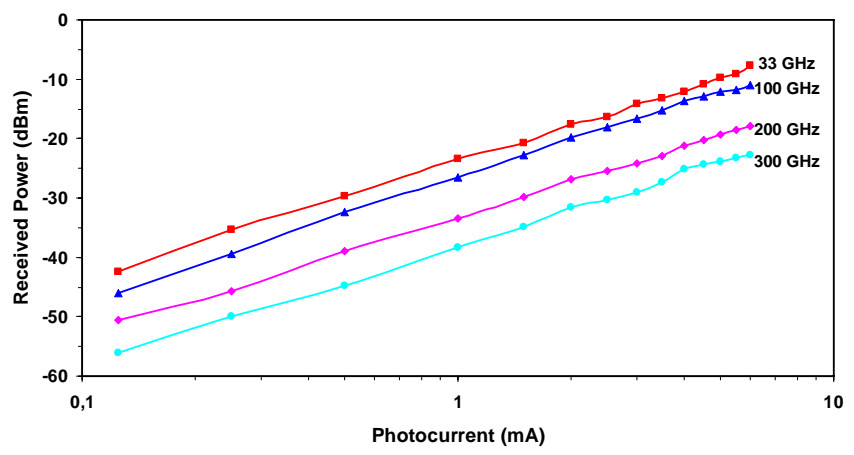

Fig. 13 High-power chip-level measurements of a LPTA-integrated photomixer at a DC-bias level of $-2 \mathrm{~V}$ and a photocurrent up to $-6 \mathrm{~mA}$ at $33 \mathrm{GHz}, 100 \mathrm{GHz}, 200 \mathrm{GHz}$ and $300 \mathrm{GHz}$.

For packaging the antenna-integrated photomixer, a quasioptical transmitter module with a SMF input was constructed comprising techniques for an efficient antenna beam generation, which was already reported in [16]. This module consists of a high-resistive (HR) silicon spacer and a hemispherical HR silicon lens for focusing the generated $\mathrm{THz}$ beam and is shown in Fig. 14. The package also features two DC pins for biasing the antenna-integrated photodetectors as well as means to couple the SMF to the POW of the antennaintegrated PD chip. 


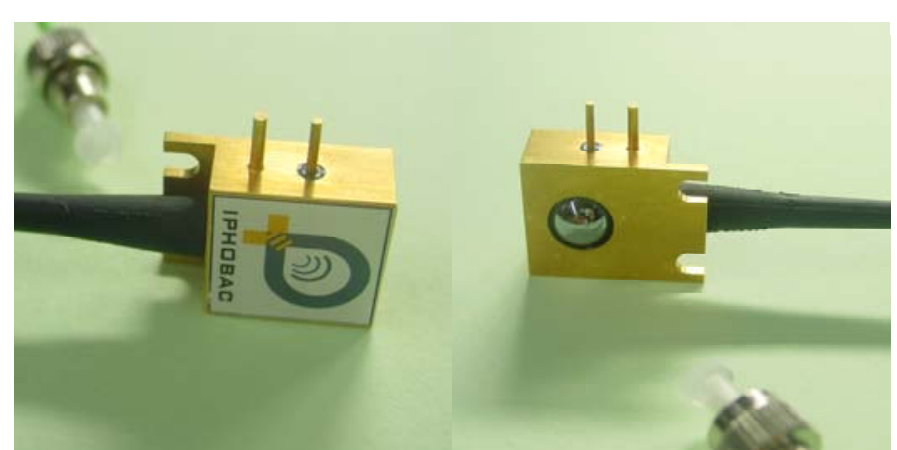

Fig. 14 Top view of a packaged antenna-integrated photomixer (left hand) and bottom view (right hand) showing the quasi-optics for efficient radiation pattern generation.

\section{V. $60 \mathrm{GHz}$ PHOTONIC WIRELESS HDTV TRANSMISSION EXPERIMENT}

In this chapter, we report on a very compact photonic millimeter-wave system for broadband wireless transmission of uncompressed HDTV signals. For photonic millimeterwave generation, we utilized the MLLD described above in unlocked condition. This severely reduces the complexity as compared to other techniques like external RF modulation, optical injection locking or optical phase locking. In conjunction with the applied modulation scheme (non-returnto-zero on-off-keying) and an incoherent wireless receiver architecture, overall system complexity is extremely low.

Fig. 16 shows the configuration of the $60 \mathrm{GHz}$ RoF system. In general, it consists of an optical carrier generation solely using the MLLD and a subsequent broadband data modulation, a wireless $60 \mathrm{GHz}$ RoF transmitter and a wireless receiver using incoherent detection. We have packaged three modules (see Fig. 15), and further presented the system at ICT2008 in Lyon, France, demonstrating a live transmission of a real HDTV signal [23].

The optical mm-wave comb generated by the MLLD is further externally modulated with non-return-to-zero on-offkeying (NRZ-OOK) data of up to $5 \mathrm{~Gb} / \mathrm{s}$ using a standard $10 \mathrm{~Gb} / \mathrm{s}$ electro-absorption modulator. In our testbed, a pseudo

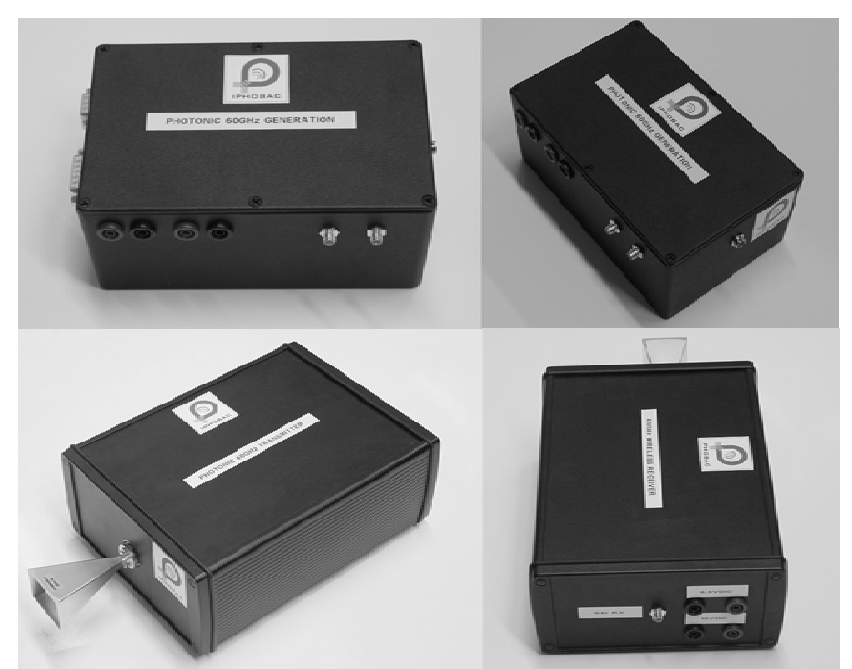

Fig. 15 Photographs of the developed subsystems. (a) and (b) show the photonic mm-wave unit, (c) the wireless $60 \mathrm{GHz}$ transmitter and (d) the wireless receiver.

random binary sequence (PRBS) with a word length of $2^{31}-1$ was applied to the modulator. For bit-error-rate (BER) characterization, the optical signal is amplified by an erbiumdoped fiber amplifier and adjusted with an optical attenuator (OA) thus controlling the transmitted RF power. After fiberoptic transmission to the wireless RoF transmitter via $50 \mathrm{~m}$ standard single mode fiber, the optical mm-wave signal is o/econverted by a $70 \mathrm{GHz} \mathrm{PD}$, amplified to a maximum RF signal level of $+10.8 \mathrm{dBm}$ and transmitted by a standard $23 \mathrm{dBi}$ horn antenna. The gain and noise figure of the power amplifier are $37.5 \mathrm{~dB}$ and $5.0 \mathrm{~dB}$, respectively. After wireless transmission, the mm-wave signal is received by an identical $23 \mathrm{dBi}$ horn antenna and amplified by a low noise amplifier (LNA) with $16 \mathrm{~dB}$ gain and a noise figure of $4.5 \mathrm{~dB}$. Further on, the envelope of the data-modulated mm-wave signal is recovered using a broadband and high-efficient GaAs Schottky detector. Finally, the detected OOK signal is amplified by an LNA for performing BER analysis. Compared to coherent detection approaches, no phase-locked loop or
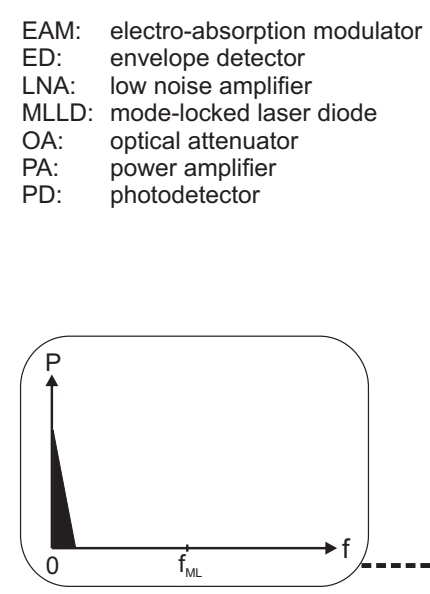
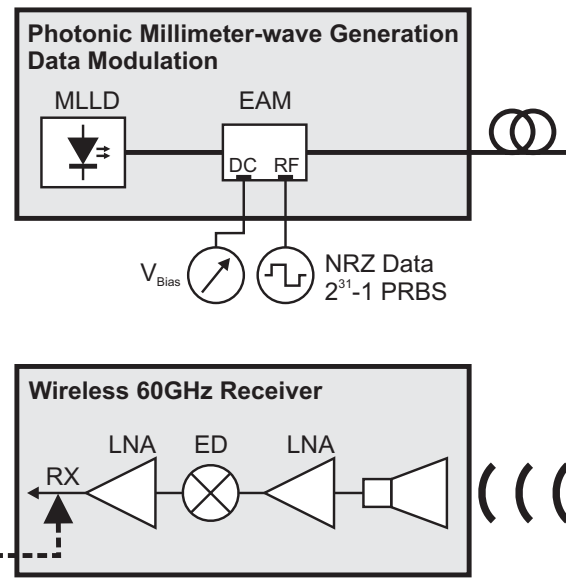

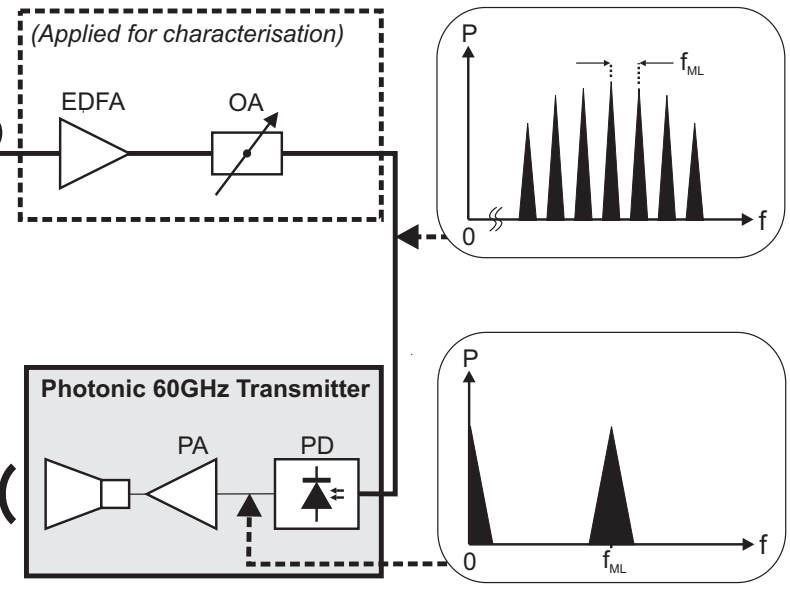

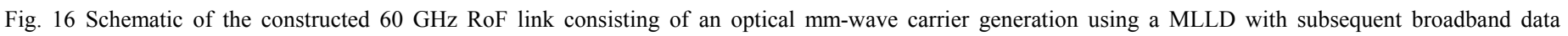
modulation, a photonic $60 \mathrm{GHz}$ transmitter and a wireless receiver. The components indicated in the dashed box are used for the characterization issues. 
local oscillator is necessary for the detection, which drastically lowers the cost for the receiver.

For investigating the link system performance the wireless signal was transmitted within a laboratory environment applying a wireless path length of $2.5 \mathrm{~m}$. Transmitter and receiver were placed in a height of approximately $120 \mathrm{~cm}$ above ground. No endeavors have been made to avoid multipath propagation. The total fiber length between MLLD and PD was set to approximately $54 \mathrm{~m}$. As a start, BER characterizations have been carried out at data rates of 1.25 , $1.5,3.0$ and $5.0 \mathrm{~Gb} / \mathrm{s}$ which are shown in Fig. 17. The transmitted power was controlled by adjusting the optical power to the $\mathrm{PD}$ with the OA. Error-free operation $\left(\mathrm{BER}<10^{-9}\right)$ was achieved for $1.25 \mathrm{~Gb} / \mathrm{s}-$ and $1.5 \mathrm{~Gb} / \mathrm{s}-$ operation, giving sensitivities of $-44.5 \mathrm{dBm}$ and $-42.5 \mathrm{dBm}$, respectively. The BER curves for 3.0 and $5.0 \mathrm{~Gb} / \mathrm{s}$-operation show error-floors of approximately $10^{-8}$ and $10^{-5}$, respectively.

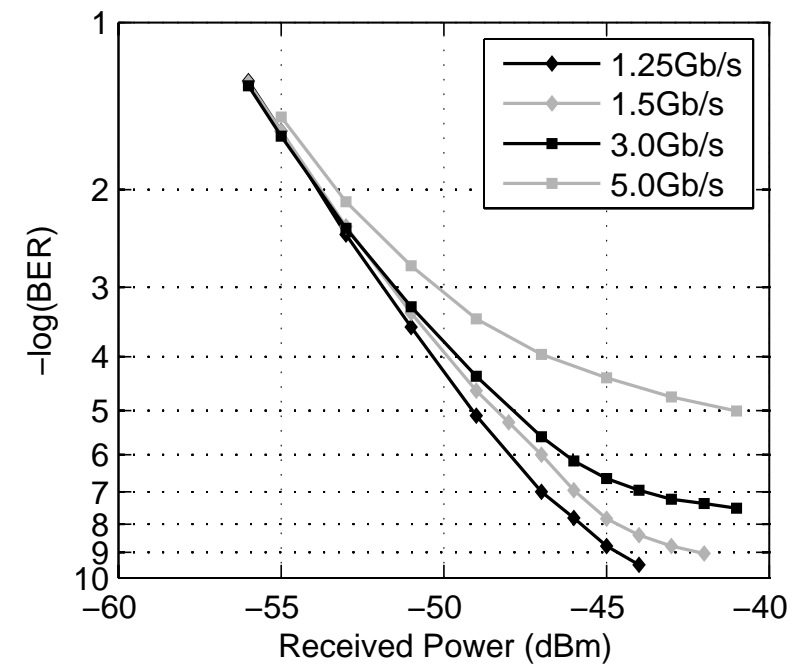

Fig. 17 Measured BER as a function of received power level for multigigabit broadband wireless data transmission over $2.5 \mathrm{~m}$ wireless span.
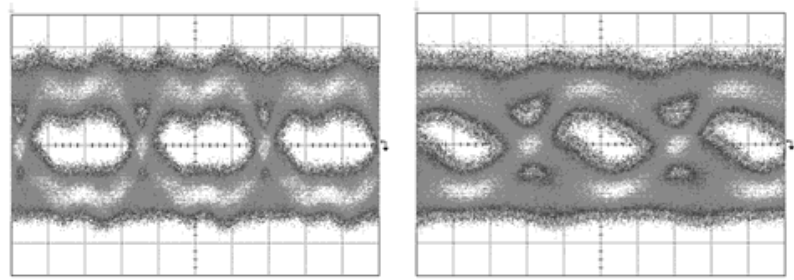

Fig. 18 Eye diagrams after $25 \mathrm{~m}$ wireless transmission for data rates of 3.0 $\mathrm{Gb} / \mathrm{s}$ (left hand) and $5.0 \mathrm{~Gb} / \mathrm{s}$ (right hand). The transmit power in the wireless RoF transmitter was fixed to $\sim-8 \mathrm{dBm}$.

Further on, we performed out-door experiments with a wireless span of $25 \mathrm{~m}$ using the same system. Fig. 18 shows measured eye diagrams at data rates of 3.0 and $5.0 \mathrm{~Gb} / \mathrm{s}$, at an RF transmit power of approx. $-8 \mathrm{dBm}$. As can be seen, the $3 \mathrm{~Gb} / \mathrm{s}$ eye is clearly open while distortions become apparent in the eye diagram for $5.0 \mathrm{~Gb} / \mathrm{s}$ transmission. Next, the receiver sensitivity was investigated for a wireless path length of $25 \mathrm{~m}$ which is shown in Fig. 19. The BER curves for 1.25, 1.5 and $3 \mathrm{~Gb} / \mathrm{s}$ are nearly congruent, exhibiting sensitivities of $-46,-45.5$ and $-45 \mathrm{dBm}$, respectively. The BER curve for

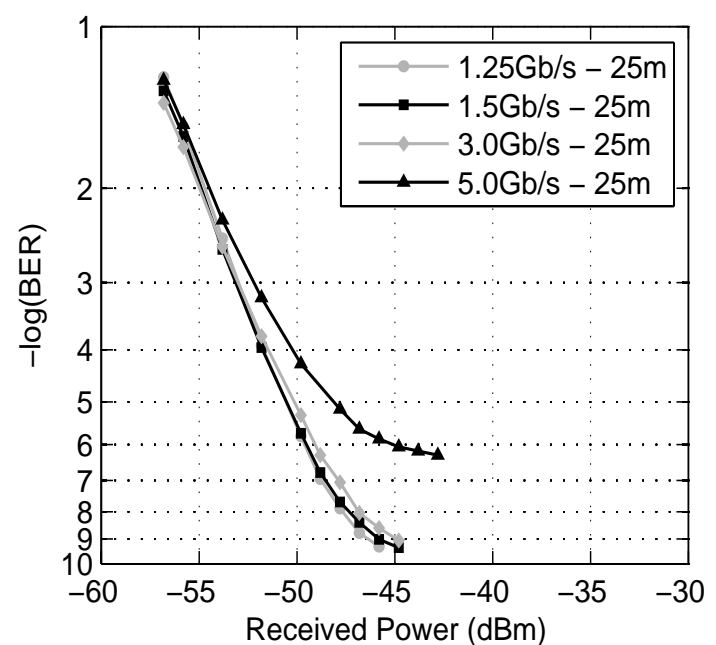

Fig. 19 Measured BER as a function of received power level for multi-gigabit broadband wireless data transmission over $25 \mathrm{~m}$ wireless span.

$5 \mathrm{~Gb} / \mathrm{s}$-operation shows an error floor at about $10^{-7}$.

Comparing the results achieved with 2.5 and $25 \mathrm{~m}$ wireless transmission, the sensitivities are slightly improved for outdoor operation although wireless distance was longer in the outdoor case. We expect this to be due to a much better SNR in the photonic transmitter, as the optical input power to the PD in the transmitter was much higher for the outdoor case. Regarding especially the $5 \mathrm{~Gb} / \mathrm{s}$-curve, we here assume the limited envelope detector's video bandwidth of about $2.7 \mathrm{GHz}$ responsible for the error-floor as all other components exhibit a sufficient bandwidth. In the experiments, we have used medium-gain antennas with a gain of $23 \mathrm{dBi}$. Considering high-gain antennas like Cassegrain or Gaussian optical lens antennas would increase the possible wireless path length to several hundreds of meters even considering atmospheric gaseous as well as rain attenuation [24].

\section{VI. $60 \mathrm{GHz}$ BROADBAND PHOTONIC WIRELESS TRANSMISSION EXPERIMENT}

The boom in mobile internet and data services leaves no doubt that today's wireless networks will very soon face a capacity crunch. Worldwide mobile data and internet traffic is doubling about every 18 month and operators encourage subscribers to mitigate from previous generation mobile standard such as GSM with a bandwidth of a few hundred kilobit per second to HSPA and LTE in the future offering a peak bandwidth of up to $150 \mathrm{Mbit} / \mathrm{s}$ [25]. As a result, future wireless backhauling in mobile networks and in access networks must be capable of providing throughputs well in the gigabit per second range.

In comparison to all-electronic wireless systems, photonic solutions generally have the edge whenever high aggregate bit rates and/or long transmission distances are involved and consequently most broadband wireless demonstrations to date employed photonic approaches [26]-[34]. We have previously reported on a photonic broadband $12.5 \mathrm{Gbit} / \mathrm{s}$ wireless system operating at $60 \mathrm{GHz}$ using ASK modulation [24], [35]. 
However, in that case the spectral efficiency in the wireless domain was below $0.5 \mathrm{bit} / \mathrm{s} / \mathrm{Hz}$ meaning that within the regulated bandwidth from $57 \mathrm{GHz}$ to $64 \mathrm{GHz}$ it was only possible to transmit a maximum throughput of about $3.5 \mathrm{Gbit} / \mathrm{s}$.

Here, we report on a compact and high spectral-efficient super-broadband photonic wireless system operating within the $7 \mathrm{GHz}$ spectral bandwidth in the $60 \mathrm{GHz}$ band. Fig. 20 shows the configuration of the $60 \mathrm{GHz}$ photonic wireless testbed. In general, the system consists of an optical mm-wave carrier generator unit with a subsequent broadband data modulation, a photonic wireless transmitter and a coherent wireless receiver.

For optical mm-wave carrier generation, light from a DFB laser source at a wavelength of $1548.9 \mathrm{~nm}$ is modulated using a single-drive $35 \mathrm{GHz}$ bandwidth Mach-Zehnder modulator (MZM-1), which is biased to the minimum transmission point (MTP) for generating an optical double-sideband signal with suppressed carrier (DSB-SC). A polarization controller is used to minimize the polarization dependent losses. The modulator is driven by a sinusoidal source with a frequency of $\mathrm{f}_{\mathrm{LO} 1}=34.7 \mathrm{GHz}$ thus creating a double-sideband RF carrier with a frequency of $69.4 \mathrm{GHz}$. With an applied power of $+13 \mathrm{dBm}$, the optical carrier suppression is measured to be approximately $19 \mathrm{~dB}$. To compensate for the modulation losses while operating at MTP, an EDFA was implemented followed by an optical band-pass filter to remove ASE noise. The signal power of the data-modulated optical mm-wave carrier is approximately $+14 \mathrm{dBm}$ at this stage.
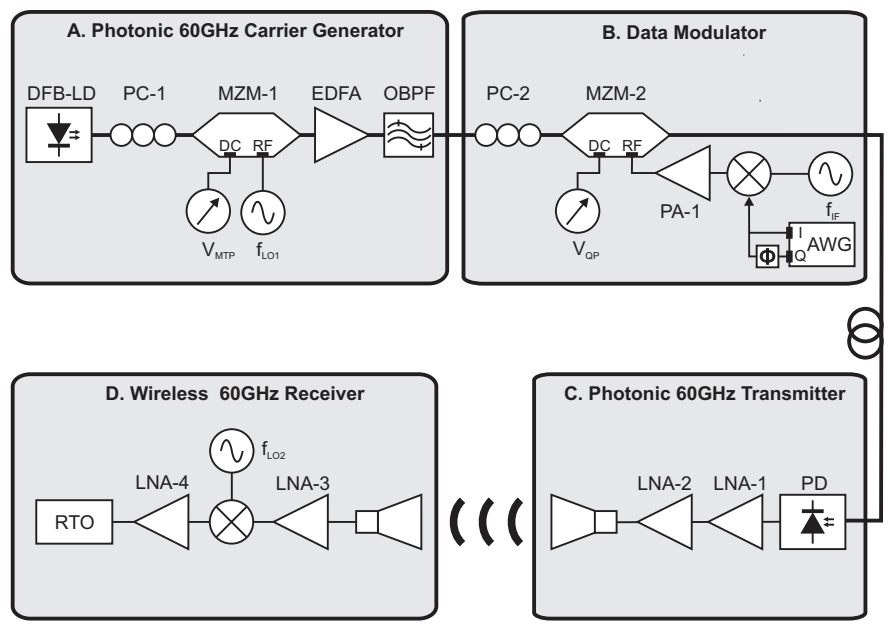

Fig. 20 Schematic of the compact $60 \mathrm{GHz}$ photonic wireless link consisting of an optical mm-wave carrier generator based upon external modulation, a subsequent broadband OFDM data modulation, a photonic wireless transmitter and a wireless coherent receiver. The configuration for wireless and back-to-back experiments is further indicated in the figure.

Photonic data modulation is performed by external modulation as well. The DC-bias is set to the quadrature point to achieve a quasi-linear modulation of the optical signal in conjunction with a sufficiently low power of the modulating data signal. A polarization controller is used before the modulator to minimize the polarization dependent loss.

The applied OFDM signal under test is created on a computer using Matlab ${ }^{\circledR}$ with an FFT block size of 2048, 2009 data subcarriers, 34 pilots and 5 null subcarriers. Total signal bandwidth is set to $7 \mathrm{GHz}$, while applying QAMmodulation for each data subcarrier. Signal generation is performed by a Tektronix AWG7102 $10 \mathrm{GS} / \mathrm{s}$ dual-output arbitrary waveform generator (AWG), where the I- and the Qcomponent of the OFDM signal are combined and applied to a mixer. A sinusoidal microwave source is applied to the LO input of the mixer to up-convert the signal to an IF carrier frequency of $8.5 \mathrm{GHz}$. The LO power level is $+24 \mathrm{dBm}$. The upconverted OFDM signal is amplified by a $18 \mathrm{~dB}$ gain power-amplifier (PA-1) to a level of approx. $3.5 \mathrm{dBm}$ and applied to the RF electrode of MZM-2.

After fiber-optic transmission to the wireless RoF transmitter, the optical mm-wave signal is o/e converted by a $70 \mathrm{GHz}$ photodetector. The converted mm-wave signal is amplified by LNA-1 with a gain of $\mathrm{G}=20 \mathrm{~dB}$ and a noise figure of $\mathrm{NF}=6 \mathrm{~dB}$ and LNA-2 $(\mathrm{G}=18 \mathrm{~dB}, \mathrm{NF}=6 \mathrm{~dB})$ to a transmit power of approx. $-1 \mathrm{dBm}$ and coupled to a $23 \mathrm{dBi}$ gain horn antenna. Considering carrier and intermediate frequency, the OFDM signal is centered at $f_{R F}-f_{I F}=60.9$ $\mathrm{GHz}$, giving a consumed bandwidth of $57.4-64.4 \mathrm{GHz}$. This does not quite exactly meet the worldwide regulatory specifications of $57-64 \mathrm{GHz}$ [36],[37]. This is due to the insufficient bandwidth of LNA-2.

The wireless receiver consists of an identical $23 \mathrm{dBi}$ horn antenna. After amplification by a low-noise amplifier LNA-3 with a gain of $\mathrm{G}=18.6 \mathrm{~dB}$ and a noise figure of $\mathrm{NF}=4.5 \mathrm{~dB}$, the signal is coupled to a low-loss custom design balanced mixer for down-conversion. The LO frequency $f_{\mathrm{LO} 2}$ is $53.2 \mathrm{GHz}$ which down-converts the mm-wave signal to an intermediate frequency centered around $7.7 \mathrm{GHz}$. This signal is further amplified by LNA-4 $(\mathrm{G}=22 \mathrm{~dB}, \mathrm{NF}=4 \mathrm{~dB})$ to a power level of approximately $+5 \mathrm{dBm}$ and coupled to a Agilent DSO91304A $13 \mathrm{GHz}$ bandwidth real time oscilloscope (RTO) with a sampling speed of $40 \mathrm{GS} / \mathrm{s}$ to capture the IF signal. Finally, OFDM demodulation and EVM evaluation are performed offline using Matlab ${ }$.

For evaluating the system performance, we have performed experiments in a laboratory environment with a fiber-optic transmission span of $10 \mathrm{~m}$ and a wireless path length of $2.5 \mathrm{~m}$. The data subcarriers of the $7 \mathrm{GHz}$ bandwidth OFDM signal are modulated with either 8- or 16-QAM OFDM signals corresponding to transmitted data rates of 20.28 and 27.04 Gbit/s, respectively. For the measurements, transmitter and receiver are placed at a height of approximately $90 \mathrm{~cm}$ above the floor level. 

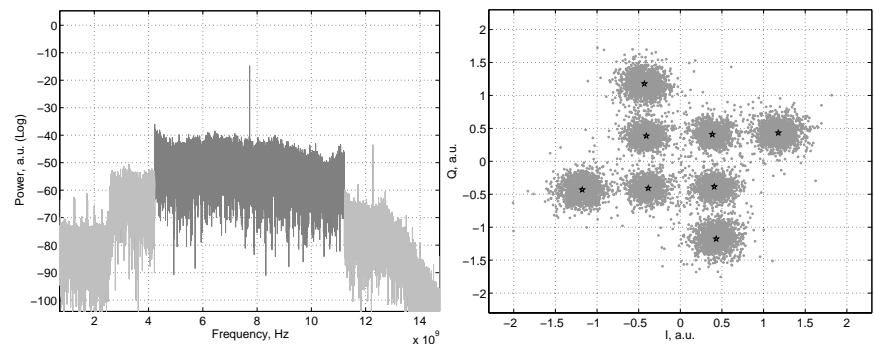

Fig. 21 Received spectrum and constellation diagram obtained after photonic up-conversion, $10 \mathrm{~m}$ fiber-optic and $2.5 \mathrm{~m}$ wireless transmission. The $7 \mathrm{GHz}$ bandwidth OFDM signal with 8-QAM subcarrier modulation gives a data transmission rate of $20.28 \mathrm{Gbit} / \mathrm{s}$.
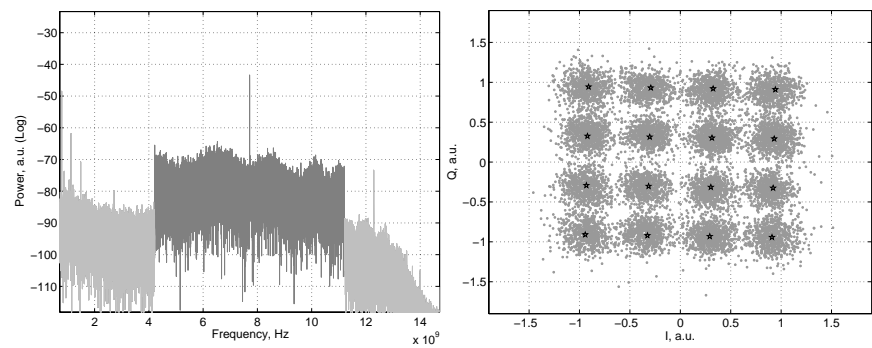

Fig. 22 Received spectrum and constellation diagram obtained after photonic up-conversion, $10 \mathrm{~m}$ fiber-optic and $2.5 \mathrm{~m}$ wireless transmission. The $7 \mathrm{GHz}$ bandwidth OFDM signal with 16-QAM subcarrier modulation gives a data transmission rate of $27.04 \mathrm{Gbit} / \mathrm{s}$.

The received spectrum and constellation diagram for $20.28 \mathrm{Gbit} / \mathrm{s}$ photonic-wireless transmission using 8-QAM subcarrier modulation are shown in Fig. 21. The measured mean EVM is $18.8 \%$ for a SNR of $18.9 \mathrm{~dB}$. From the EVM, a BER of $2.20 \cdot 10^{-4}$ can be computed which is below the forward error correction (FEC) limit of $2.2 \cdot 10^{-3}$ [38].

We further demonstrated 16-QAM modulated OFDM transmission, which corresponds to a data rate of $27.04 \mathrm{GHz}$ at a bandwidth of $7 \mathrm{GHz}$. The received spectrum and the constellation diagram are shown in Fig. 22. The measured mean EVM is here $17.6 \%$ for a SNR of $21.5 \mathrm{~dB}$. From the EVM, a BER of $4.2 \cdot 10^{-3}$ can be computed, which is slightly above the FEC limit [38].

\section{CONCLUSION}

We described broadband photonic wireless transmission links in the $60 \mathrm{GHz}$ band with record data rates up to $27 \mathrm{~Gb} / \mathrm{s}$. Optical frequency comb generation by using self-pulsating mode-locked lasers and high output power photodetectors which are key devices for high-performance wireless systems were developed and reported. We also demonstrated 30-300 GHz tunable mm-wave frequency generation utilizing packaged antenna integrated photomixers.

\section{ACKNOWLEDGMENT}

This work was supported by the European Commission and carried out within in the framework of the European integrated project IPHOBAC under grant no. 35317.

\section{REFERENCES}

[1] J. Capmany, D. Novak, "Microwave photonics combines two worlds," Nature Photonics, vol. 1, pp. 319-330, 2007.

[2] A. J. Seeds, "Microwave photonic links," Microwave Photonics, 2004 IEEE International Topical Meeting on, 2004, pp. 16-19.

[3] "Special Issue on Microwave Photonics," Journal of Lightwave Technology. vol. 26, T. E. Darcie, A. Stöhr, and P. K. L. Yu, Eds., 2008, pp. 2333-2816.

[4] A. Stöhr, "Pushing the Boundaries," IEEE Microwave Magazine, vol. 10, no. 6, pp. 106-115, 2009.

[5] www.ist-iphobac.org.

[6] F. van Dijk, A. Enard, X. Buet, F. Lelarge, G.-H. Duan, "Phase Noise Reduction of a Quantum Dash Mode-Locked Laser in a MillimeterWave Coupled Opto-Electronic Oscillator," Journal of Lightwave Technology, vol. 26, no. 15, pp. 2789-2794, Aug. 2008.

[7] F. Lelarge, B. Dagens, J. Renaudier, R. Brenot, A. Accard, F. van Dijk, D. Make, O. Le Gouezigou, J.-G. Provost, F. Poingt, J. Landreau, O. Drisse, E. Derouin, B. Rousseau, F. Pommereau, G.-H. Duan, "Recent Advances on InAs/InP Quantum Dash Based Semiconductor Lasers and Optical Amplifiers Operating at $1.55 \mu \mathrm{m}$," Invited paper, IEEE Journal of Selected Topics in Quantum Electronics, vol. 13, no. 1, pp. 111-124, Jan. 2007.

[8] F. van Dijk, A. Enard, A. Akrout, G.-H. Duan, F. Lelarge, "Optimization of a $54.8 \mathrm{GHz}$ coupled opto-electronic oscillator through dispersion compensation of a mode-locked semiconductor laser," Microwave Photonics, 2008 IEEE International Topical Meeting on, Sept. 2008, pp. 279-282.

[9] H. Ito, S. Kodama, Y. Muramoto, T. Furuta, T. Nagatsuma, T. Ishibashi, "High-speed and high-output InP-InGaAs unitraveling-carrier photodiodes," IEEE J. of Selected Topics in Quantum Electron, vol. 10, pp. 709-27, 2004.

[10] C. C. Renaud, M. Robertson, D. Rogers, R. Firth, P. J. Cannard, R. Moore, A. J. Seeds, "A high responsivity, broadband waveguide unitravelling carrier photodiode," Proceedings of SPIE Photonics Europe, 2006, pp. 61940C-1-61940C-8.

[11] A. Madjar, N. Koka, J. Bloch, P. K. L. Yu, A. Stöhr, D. S. Jäger, “A novel analytical model as a design tool for uni-traveling-carrier traveling wave photo detectors approaching $1 \mathrm{THz}$," IEEE Trans. Microwave Theory and Tech., vol 57, no 1, pp. 223-30, Jan. 2009.

[12] C. C. Renaud, D.G. Moodie, D. C. Rogers, P. J. Cannard, R. Firth, A. Borghesani, M. Robertson, A. J. Seeds, "High Output Power at $110 \mathrm{GHz}$ with a Waveguide Uni-Travelling Carrier photodiode," Lasers and Electro-Optics Society, 2007, Paper ThM3.

[13] G. Maxwell et al, "Very low coupling loss, hybrid-integrated all-optical regenerator with passive assembly" Optical Communication, 2002. ECOC 2002. 28th European Conference on, 8-12 Sept. 2002.

[14] A. J. Seeds, C. C. Renaud, M. Pantouvaki, M. Robertson, I. Lealman, D. Rogers, R. Firth, P. J. Cannard, R. Moore, R. Gwilliam, "Photonic synthesis of THz signals," Invited paper, 36th European microwave conference, Manchester (UK), 2006.

[15] L. Ponnampalam, C. C. Renaud, I. F. Lealman, L. Rivers, P. Cannard, M. J. Robertson, D. Moodie, F. van Dijk, A. Enard, F. Blache, M. Goix, F. Mallecot, A. J. Seeds, "Injection-locked Integrated Twin DBR Lasers for mm-wave Generation," European Workshop on photonic solutions for wireless, access, and in-house networks, Duisburg, Germany, 2009.

[16] M. Weiß, A. G. Steffan, S. Fedderwitz, G. Tsianos, A. Stöhr, D. Jäger, "Highly-Compact Fibre-Optic Package for $30-300 \mathrm{GHz}$ Wireless Transmitter Modules," 2nd Electronics System-Integration Technology Conference, London, UK, pp. 1111-1114, 2008.

[17] K. J. Williams, "Comparisons between dual-depletion-region and unitravelling-carrier p-i-n photodetectors," IEE Proc.-Optoelectron., vol. 149, no. 4, Aug. 2002.

[18] D. A. Tulchinsky, X. Li, N. Li, S. Demiguel, J. C. Campbell, K. J. Williams, "High-Saturation Current Wide-Bandwidth Photodetectors," IEEE Journal of Selected Topics in Quantum Electronics, vol. 10, no. 4, July/Aug. 2004.

[19] A. Stöhr, A. Malcoci, A. Sauerwald, I. C. Mayorga, R. Güsten, D. Jäger, "Ultra-wideband traveling-wave photodetectors for photonic local oscillators," IEEE Journal of Lightwave Technology, vol. 21, no. 12, pp. 3062-3070, 2003. 
[20] A. Malcoci, A. Stöhr, K. Lill, F. Siebe, P. van der Wal, A. Sauerwald, R. Güsten, D. Jäger, "Optical submillimeter-wave generation employing antenna integrated ultra-fast travelling-wave $1.55 \mu \mathrm{m}$ photodetectors," IEEE MTT-S International Microwave Symposium - IMS 2003, vol. 1, pp. 143-146, 2003.

[21] A. Stöhr, R. Heinzelmann, A. Malcoci, D. Jäger, "Optical heterodyne millimeter-wave generation using $1.55 \mu \mathrm{m}$ traveling-wave photodetectors," IEEE Trans. Microwave Theory and Tech., vol. 49, no. 10, pp. 1926-1933, 2001.

[22] J. Klamkin, A. Ramaswamy, N. Nunoya, L. A. Johansson, J. E. Bowers, S. P. DenBaars, L. A. Coldren, "Uni-traveling-carrier waveguide photodiodes with $>40 \mathrm{dBm}$ OIP3 for up to $80 \mathrm{~mA}$ of photocurrent," IEEE J. Quantum Technol., vol. 44, pp. 354-359, 2008.

[23] ICT2008, Lyon, France, Nov. 25-27, 2008, http://ec.europa.eu/information_society/events/ict/2008/exhibition/comp etition/index en.htm.

[24] M. Weiss, M. Huchard, A. Stöhr, B. Charbonnier, S. Fedderwitz, D. Jäger, "60-GHz Photonic Millimeter-Wave Link for Short- to MediumRange Wireless Transmission Up to $12.5 \mathrm{~Gb} / \mathrm{s}$," Journal of Lightwave Technology, vol. 26, no. 15, pp. 2424-2429, Aug. 2008.

[25] John McNicol, "Millimeter Wave for the Backhaul Capacity Crunch", Microwave Engineering Europe, September 2009.

[26] J. Yu, J. Hu, D. Qian, Z. Jia, G. K. Chang, and T. Wang, "Transmission of microwave-photonics generated 16Gbit/s super broadband OFDM signals in radio-over-fiber system," Conference on Optical Fiber communication/National Fiber Optic Engineers Conference, Feb. 2008, pp. 1-3.

[27] T. Nagatsuma et al., "Millimeter-wave photonic integrated circuit technologies for high-speed wireless communications applications," 2004 IEEE International Solid-State Circuits Conference, vol. 1, pp. 448-449, 2004.

[28] A. Hirata et al., "120-GHz-band millimeter-wave photonic wireless link for 10-Gbit/s data transmission," IEEE Trans. Microw. Theory Tech., vol. 54, no. 5, May 2006.

[29] K. Ohata, K. Maruhashi, M. Ito, S. Kishimoto, K. Ikuina, T. Hashiguchi, K. Ikeda, and N. Takahashi, "1.25 Gbps wireless Gigabit Ethernet link at 60GHz-band," IEEE MTT-S Int. Microw. Symp. Dig., vol. 1, pp. 373376, June 2003.

[30] T. Taniguchi, N. Sakurai, K. Kumozaki, T. Imai, "Loop-Back Optical Heterodyne Technique for 1.0-Gbit/s Data Transmission Over $60-\mathrm{GHz}$ Radio-On-Fiber Uplink," IEEE Journal of Lightwave Technology, vol. 25, no. 6, pp. 1484-1494, June 2007.

[31] R. W. Ridgway, and D. W. Nippa, "Generation and modulation of a 94GHz signal using electrooptic modulators," IEEE Photon. Technol. Lett., vol. 20 , no. 8 , pp. $653-555,2008$.

[32] M. Luise, F. Giannetti, R. Reggiannini, "Mobile and personal communications in the $60 \mathrm{GHz}$ band: a survey," Wireless Personal Communications, vol. 10, no. 2, pp. 207-243, July 1999.

[33] B. Charbonnier et al., "Upcoming perspectives and future challenges for ROF," Microwave Photonics, 2007 IEEE International Topical Meeting on, Oct. 2007, pp. 21-23.

[34] M. Huchard et al, "Ultra broad band wireless home network based on $60 \mathrm{GHz}$ WPAN cells interconnected via RoF," Special Issue of the IEEE Trans. Microw. Theory Tech. and J. Lightw. Techn., 2008.

[35] A. Stöhr, A. Akrout, R. Buß, B. Charbonnier, F. van Dijk, A. Enard, S. Fedderwitz, D. Jäger, M. Huchard, F. Lecoche, J. Marti, R. Sambaraju, A. G. Steffan, A. Umbach, M. Weiß, "60 GHz Radio-over-Fiber Technologies for Broadband Wireless Services," J. Opt. Networking., vol. 8, no. 5, pp. 471-487, 2009, (invited).

[36] Code of Federal Regulation, title 47 Telecommunication, chapter 1, part 15.255, Federal Communication Commission, 2004.

[37] RSS-210: Low-power Licence-exempt Radiocommunication Devices (All Frequency Bands), Industry Canada Spectrum Management and Telecommunications, 2007.

[38] J. G. Proakis, Digital Communications, 3rd ed., McGraw-Hill, Ed., 1999. 


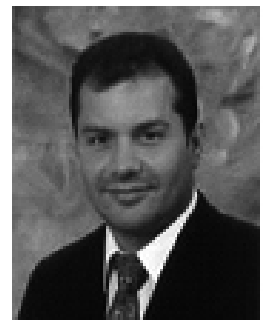

Andreas Stöhr received the Dipl.-Ing. and Dr.-Ing. degree in Electrical Engineering from GerhardMercator-University Duisburg (GMUD), Germany, in 1991 and 1997, respectively. Since 1995 he is a member of ZHO-Optoelektronik at Universität Duisburg-Essen, Germany. In 1998 and 1999 he joined the Communications Research Laboratory (CRL), Ministry of Posts and Telecommunications, Japan. His current research interests include the design and fabrication of III/V based microwave photonic devices and their application in microwave or millimeter-wave fiberoptic transmission systems as well as in optical sensors. He has published more than 100 papers in refereed journals and conferences.

Dr. Stöhr received the 1997 Annual Award from the DUG. He was conference chair of the Photonics Europe - Millimeter wave \& THz Photonics conference and for many years he is serving as a TPC member many international conferences including the International Topical Meeting on Microwave Photonics and the LEOS annual meeting. Dr. Stöhr is a senior member of the IEEE. He is currently engaged in advanced and ultrafast photonic components for optical millimeter-wave and $\mathrm{THz}$ generation. $\mathrm{He}$ is also active in the field of broadband millimeter-wave photonic wireless systems using radio-over-fiber ( $\mathrm{RoF})$ techniques.

Paul Cannard, photograph and biography not available at the time of publication.

Benoît Charbonnier was born in Versailles (France) in 1971. He received his engineering degree in 1994 from Ecole Nationale Supérieure des Télécommunications de Paris and received his Ph.D. degree in 1997 on 40Gbps soliton transmission from the same institution.

In 1997, he joined Nortel Network in Harlow (U.K) in the advanced communications group where he worked on $80 \mathrm{~Gb} / \mathrm{s}$ long haul transmission and then, in 2001, joined Marconi Communications to develop an Ultra-Long Haul $10 \mathrm{~Gb} / \mathrm{s}$ based transmission product. Since 2004, he has been working as a research engineer at France Télécom Research and Development, focusing on next generation optical access network, especially in-building networks with radio over fiber techniques.

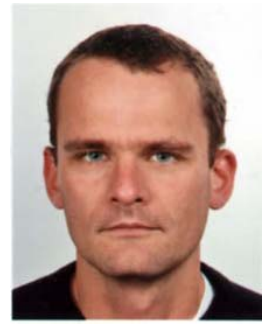

Frédéric van Dijk was born in Chevreuse, France, in 1972. He received the Ph.D. degree from Université Paul Sabatier of Toulouse, Toulouse, France, in

1999. His Ph.D. work, performed at LAAS-CNRS, Toulouse, dealt with the growth, process, and characterization of $\mathrm{AlGaAs} / \mathrm{GaAs}$ VCSEL structures. In 2000, he joined THALES Research and Technology, Orsay, France. He is currently working at the Alcatel-Thales III-V Lab, Palaiseau, France, on design, fabrication, and characterization of laser sources for microwave and millimeter-wave applications. He is in particular involved in studies on directly modulated DFB lasers, mode-locked lasers for frequency synthesis and clock recovery, and microwave photonic systems.

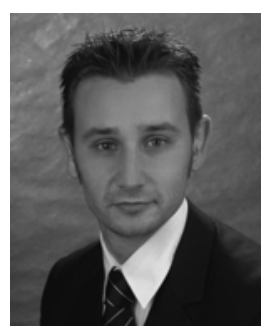

Sascha Fedderwitz was born in Mülheim an der Ruhr, Germany, on November 17, 1977. He received his Diplom-Ingenieur degree in electrical engineering from Universität Duisburg-Essen, Duisburg, Germany in 2006.

In 2007, he joined the Optoelectronics Department at Universität Duisburg-Essen, Germany. His current research involves the generation of millimeter-waves.

Dave Moodie (Member IEEE '95) was born in Leicester, U.K. He received the B.Sc. degree in physics from the University of Durham U.K. in 1989, a M.Sc. degree in telecommunications engineering from the University of London U.K. in 1995, and a PhD from Imperial College London, U.K. in 2002.

In 1989 he joined BT Laboratories, UK and worked on the development of a range of optoelectronic components. From $2000-2003$ he was a project manager at Corning Research Centre, UK. Since 2003 he has worked for CIP Technologies, UK. His main roles are product management, project management and device design. Areas of technical interest include electroabsorption modulators, photonic integration, photodiodes, and $\mathrm{THz}$ technologies.

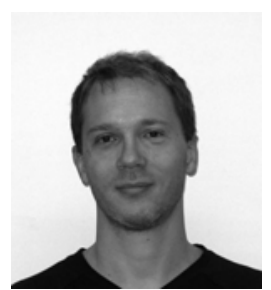

Leon Pavlovic received his Ph.D. degree from the University of Ljubljana, Slovenia, in 2006. He is currently a senior researcher at the Faculty of Electrical Engineering, University of Ljubljana. His research interests include high-speed electronics, high-frequency circuit and 3D-structure modeling, radio-frequency, millimeter-wave and optical communications.

Lalitha Ponnampalam received her BEng degree from University College London in 1992, MSEE degree from School of Optics, University of Central Florida, USA in 1998 and the $\mathrm{PhD}$ degree from University of Cambridge, United Kingdom in 2002.

In 2001, she joined Marconi Optical Components in Caswell, United Kingdom which became part of Bookham Technology and subsequently Oclaro, Inc. and worked primarily on the design and development of widely tunable semiconductor lasers. Later she joined the Ultrafast Photonics Group at the Department of Electronic and Electrical Engineering, University College London in 2007 to work on the European Integrated project IPHOBAC funded by the European Commission, focussing on ultrafast photonic components for millimetre-wave generation and photonic integration.

Cyril C. Renaud was born in Paris, France, in 1973. He received the degree of engineering from the Ecole Supérieure d'Optique, Orsay, France, and the Diplôme d'Etudes Approfondies (D.E.A.) in Optics and Photonics from the University Paris XI, Orsay, France, in 1996. He spent one year as a project engineer with Sfim-ODS, working on the development of microchips lasers. $\mathrm{He}$, then, worked within Optoelectronics Research Centre, University of Southampton, Southampton UK, on diode pumped high-power ytterbiumdoped fibre-lasers, with particular interest on Q-switched system and 980-nm generation. This work led to the award of a PhD in 2001.

$\mathrm{He}$ is currently a lecturer and site director of a doctoral training centre at University College London, UK, where he is working on optoelectronic devices and systems. His current research includes works on uncooled WDM sources, agile tuneable laser diode and monolithic optical frequency comb generator using Quantum Confined Stark Effect, high frequency photodetectors (UTC, travelling wave) and optical frequency generation systems in the optical and millimetre wave domains (DWDM, THZ).

Dave Rogers, photograph and biography not available at the time of publication.

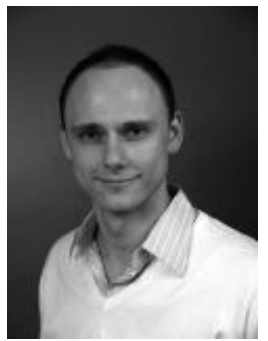

Vitaly Rymanov was born in Kiev, Ukraine, on October 7, 1980. He received his Diplom-Ingenieur degree in electrical engineering from Universität Duisburg-Essen, Duisburg, Germany in 2008.

His current research involves the development of THz-traveling-wave photomixers with coplanar output and integrated antennas.

Alwyn Seeds, photograph and biography not available at the time of publication.

Andreas Steffan, photograph and biography not available at the time of publication.

Andreas Umbach, photograph and biography not available at the time of publication. 


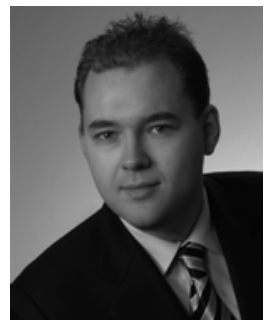

Mario Weiß was born in Regensburg, Germany, on April 20, 1979, Germany. He received his DiplomIngenieur degree in electrical engineering from Ruhr-Universität Bochum, Bochum, Germany in 2006.

In 2006, he joined the ZHO-Optoelektronik Department at Universität Duisburg-Essen, Germany. His current research involves radio-overfiber systems and millimeter-wave generation. 